\title{
Componentes estruturais do resíduo pós-corte em capim-massai adubado com cinco doses de nitrogênio ${ }^{1}$
}

\author{
After cut structural components of massai grass under five nitrogen fertilizer levels
}

\author{
Marcos Neves Lopes²*, Magno José Duarte Cândido ${ }^{3}$, Roberto Cláudio Fernandes Franco Pompeu ${ }^{4}$, Rodrigo \\ Gregório da Silva ${ }^{5}$ e Francisco Marcus Lima Bezerra ${ }^{6}$
}

\begin{abstract}
Resumo - Objetivou-se avaliar os componentes da biomassa do resíduo pós-corte em capim-massai submetido a cinco doses de nitrogênio $\left(0 ; 150 ; 300 ; 450\right.$ e $600 \mathrm{mg} \mathrm{N} \mathrm{dm}^{-3}$ de solo) num delineamento inteiramente casualizado, com cinco repetições (vasos) em casa de vegetação. Avaliaram-se a altura residual, a densidade populacional de perfilhos (DPP), a massa seca de forragem total residual (MSFTr), de forragem verde residual (MSFVr), de forragem morta residual (MSFMr), de lâmina foliar verde residual (MSLVr), de colmo verde residual (MSCVr), relação lâmina foliar/ haste (LF/C), a massa seca radicular (MS radicular) e a relação parte aérea/raiz. Observou-se efeito quadrático dos níveis de adubação nitrogenada sobre a altura residual. As variáveis MSFTr, MSFVr e MSCVr responderam positivamente, enquanto a MSLVr revelou comportamento quadrático com os níveis de N. Constatou-se valores estimados de 13,35 e 39,73 g MS/vaso para MSFTr, de 9,71 e 24,69 g MS/vaso para MSFVr e de 3,65 e 15,07 g MS/vaso para MSFMr nas doses de 0 a $600 \mathrm{mg} \mathrm{N} \mathrm{dm}^{-3}$ de solo, respectivamente. A MS radicular respondeu positivamente às doses de $\mathrm{N}$. A adubação nitrogenada proporciona resultados positivos sobre as características estruturais do resíduo pós-corte do capim-massai.
\end{abstract}

Palavras-chave - Adubação nitrogenada. Massa seca de lâmina foliar residual. Panicum maximum x Panicum infestum.

\begin{abstract}
After cut residue of Massai grass under five nitrogen fertilized levels were evaluated. A completely randomized design with five nitrogen levels $\left(0 ; 150 ; 300 ; 450\right.$ and $600 \mathrm{mg} \mathrm{N} \mathrm{dm}^{-3}$ of soil) and five replicates (plots) in greenhouse was used. It was evaluated the residual canopy height $(\mathrm{RCH})$, the tiller population density (TPD), the total residual forage dry mass (TFDM), the residual green forage dry mass (GFDM), the senescent forage dry mass (SFDM), the residual green leaf dry mass (GLDM), the residual green culm dry mass (GCDM), leaf/culm ratio (L/C), root dry mass $(\mathrm{RDM})$ and above ground/root ratio (A/R). There was square effect of nitrogen fertilization on $\mathrm{RCH}$. There were crescent and linear effect of nitrogen fertilization on TFDM, GFDM and GCDM. There was square effect of nitrogen fertilization on GLDM. The values were estimated in 13.35 and $39.73 \mathrm{~g} \mathrm{DM} / \mathrm{plot}$ to TFDM; 9.71 and 24.69 $\mathrm{g}$ DM/plot to GFDM and 3.65 and $15.07 \mathrm{~g} \mathrm{DM} /$ plot to SFDM on 0 and $600 \mathrm{mg} \mathrm{N} \mathrm{dm}^{-3}$ of soil, respectively. The RDM presented positively response to the $\mathrm{N}$ levels. It was concluded that the nitrogen fertilizing brought benefits for all structural characteristics after cut of Massai grass.
\end{abstract}

Key words - Nitrogen fertilization. Residual green leaf blade dry mass. Panicum maximum x Panicum infestum.

\footnotetext{
* Autor para correspondência

${ }^{1}$ Recebido para publicação em 27/04/2010; aprovado em 11/03/2011

Parte da Monografia do primeiro autor. Pesquisa financiada pelo MEC/SESu

${ }^{2}$ Programa de Pós-Graduação em Zootecnia/UFC, Fortaleza-CE, Brasil, nevesvv@yahoo.com.br

${ }^{3}$ Pesquisador do CNPQ e Tutor do PET Zootecnia, Departamento de Zootecnia, CCA/UFC, Fortaleza-CE, Brasil, magno@ufc.br

${ }^{4}$ Empresa Brasileira de Pesquisa Agropecuária, Centro Nacional de Pesquisa Caprinos e Ovinos, Sobral-CE, Brasil, rpompeu@cnpc.embrapa.br

${ }^{5}$ Instituto Federal de Educação, Ciência e Tecnologia/IFCE, Campus Avançado do Tauá, Tauá-CE, Brasil, rodrigogregorio@hotmail.com

${ }^{6}$ Departamento de Engenharia Agrícola, CCA/UFC, Fortaleza-CE, Brasil, mbezerra@ufc.br
} 


\section{Introdução}

A adubação nitrogenada constitui prática de manejo relevante quando se deseja aumentar a produtividade dos pastos (DURU; DUCROCQ, 2000; FAGUNDES et al., 2006), em função da resposta crescente proporcionada pela mesma, sobre a produção de massa seca das plantas forrageiras (MAGALHÃES et al., 2006). Entretanto, devese levar em consideração outros aspectos do manejo, como o uso de uma forrageira com alta capacidade de produção, estabelecimento dos pastos em solo de boa fertilidade e fracionamento das doses de adubo nitrogenado.

Além dos aspectos mencionados, deve-se atentar para um monitoramento rigoroso da condição residual do dossel forrageiro, visto que, a persistência e vigor da rebrotação nos ciclos posteriores dependerão da participação do componente folha na massa de forragem remanescente (REZENDE et al., 2008) e das reservas armazenadas nas demais partes do vegetal (base do colmo e raízes).

A estrutura residual da pastagem exerce fundamental relevância na capacidade das gramíneas forrageiras persistirem dentro de um sistema de desfolhações freqüentes (BRISKE, 1996), que dependendo da intensidade do corte ou pastejo, haverá alterações na estrutura do dossel (plasticidade fenotípica) ao longo de seu desenvolvimento, conforme o manejo adotado. A massa seca de lâmina foliar verde e o índice de área foliar residual têm papel fundamental na rebrotação do pasto, pois a área foliar verde remanescente após o pastejo é diretamente proporcional à taxa de fotossíntese líquida do pasto (GOMIDE et al., 2002). Além disso, quanto maior for a proporção de lâminas foliares remanescentes, menor é a necessidade da planta em mobilizar suas reservas orgânicas para retomar seu crescimento. Outro componente relevante é a altura residual, visto que a mesma pode influenciar o acúmulo e a composição morfológica da forragem produzida (PENA et al., 2009). Através da altura de corte preconizada, pode-se controlar o alongamento de colmos, fração indesejável e de composição bromatológica inferior àquela de lâminas foliares, apresentando baixo valor nutritivo (DIFANTE, 2009), porém, deverá ser feito dentro dos limites de tolerância da planta à desfolhação, de forma a não comprometer a persistência do pasto.

O suprimento de nutrientes em especial do nitrogênio após o corte ou pastejo assume relevante papel para a rápida recuperação das plantas sob desfolhações freqüentes, permitindo uma rebrotação com elevada taxa de alongamento de folhas e aparecimento de novos perfilhos (MARTUSCELLO et al., 2006), fatores diretamente relacionados à produção de massa seca da planta forrageira. $\mathrm{O}$ perfilhamento é uma característica estrutural determinante da plasticidade fenotípica nas plantas forrageiras, influenciada por combinações de fatores nutricionais, ambientais e de manejo sobre as características morfogênicas (GARCEZ NETO et al., 2002).

Uma boa condição residual da pastagem, propiciada pela adubação nitrogenada refletirá no aumento em biomassa total (GARCEZ NETO et al., 2002), o que propiciará em maior cobertura de solo, conferindo provavelmente maior retenção de água e permitindo resposta positiva no crescimento das plantas. Dessa forma, danos como compactação e aumento na densidade do solo, redução na biomassa radicular e perdas da água superficial, que consequentemente, irá diminuir a biomassa de forragem produzida e acelerar o processo de degradação das pastagens (MORAES, 1991), poderão ser minimizados por um manejo que proporcione condição residual adequada, refletindo em boa cobertura do solo e perenidade da pastagem.

Diante do exposto, este estudo foi conduzido com o objetivo de avaliar os componentes estruturais do resíduo pós-corte em Panicum maximum $x$ Panicum infestum cv. Massai adubado com cinco doses de nitrogênio.

\section{Material e métodos}

A pesquisa foi conduzida em casa de vegetação, pertencente ao Departamento de Fitotecnia da Universidade Federal do Ceará - UFC, em Fortaleza - CE, no período de junho a dezembro de 2008. A cidade de Fortaleza/CE está localizada a uma altitude média de 21 metros, com as seguintes coordenadas geográficas: latitude Sul de $03^{\circ} 45^{\prime} 47^{\prime}$, , longitude Oeste de $38^{\circ} 31^{\prime} 23^{\prime}$ ', com clima do tipo Aw', tropical chuvoso, segundo classificação de Köeppen. Diariamente, foram registradas as temperaturas mínimas e máximas, apresentando valores médios de 25,8 e $40,5^{\circ} \mathrm{C}$ (estabelecimento), 25,6 e 40,6 ${ }^{\circ} \mathrm{C}$ (rebrotação 1), 25,9 e $40,9^{\circ} \mathrm{C}$ (rebrotação 2), respectivamente.

Foram avaliadas cinco doses de nitrogênio (0; $150 ; 300 ; 450$ e $600 \mathrm{mg} \mathrm{dm}^{-3}$ de $\mathrm{N}$ ) equivalentes a 0 ; $300 ; 600 ; 900$ e $1200 \mathrm{~kg} \mathrm{ha}^{-1} \mathrm{ano}^{-1}$ de N, distribuídas num delineamento inteiramente casualizado com cinco repetições, totalizando 25 unidades experimentais.

O "solo" utilizado durante o período experimental foi um Argissolo amarelo, que possui como material de origem sedimentos areno-argilosos da formação barreira. Após coletado, o "solo" passou por um peneiramento, buscando-se uma melhor homogeneização e retenção de materiais grosseiros. As amostras de solo, relativas à camada de $0-20 \mathrm{~cm}$ de profundidade revelaram a seguinte composição química: $4 \mathrm{mg} \mathrm{dm}^{-3} \mathrm{de} \mathrm{P} ; 76 \mathrm{mg} \mathrm{dm}^{-3}$ de K ;

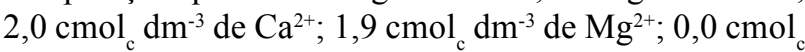
$\mathrm{dm}^{-3} \mathrm{Al}^{3+} ; 11 \mathrm{mg} \mathrm{dm}^{-3} \mathrm{de} \mathrm{Na}^{+} ; 9,10 \mathrm{~g} \mathrm{~kg}^{-1}$ de M.O; SB: 
$4,14 \mathrm{cmol}_{\mathrm{c}} \mathrm{dm}^{-3}$; CTCt: 4,14 $\mathrm{cmol}_{\mathrm{c}} \mathrm{dm}^{-3} ; \mathrm{pH}$ em água de 5,7; 19 ppm de $\mathrm{Fe}^{2+} ; 0,14$ ppm de $\mathrm{Cu}^{2+} ; 3,91 \mathrm{ppm}$ de $\mathrm{Zn}^{2+}$ e 12,18 ppm de Mn, sendo corrigidos, conforme recomendação do CFSEMG (1999), para níveis de fertilidade sugeridos para gramíneas de alto potencial produtivo e com alto nível de produção.

Os vasos foram distribuídos aleatoriamente dentro da casa de vegetação. No momento do enchimento dos vasos com capacidade de $10 \mathrm{dm}^{3}$ cada, foi feita a correção do solo, aplicando-se uma dose de calcário calcítico de 6,17 g/vaso, equivalente a $1.233 \mathrm{~kg} \mathrm{ha}^{-1}$, de acordo com análise de fertilidade, buscando-se a elevação do teor de cálcio e do $\mathrm{pH}$. Durante um período de dez dias as amostras receberam irrigação diária, visando-se a acelerar a reação do corretivo.

O controle da lâmina de irrigação diária a ser aplicada foi feito com a instalação de tensiômetros de mercúrio (Hg) nos vasos (dois tensiômetros por tratamento), sendo efetuada a reposição de água quando a coluna de mercúrio (h) atingia aproximadamente $10,0 \mathrm{~cm}$ nos tratamentos supridos com maiores doses de nitrogênio. A dose de 600 $\mathrm{mg} \mathrm{N} \mathrm{dm}{ }^{-3}$ de solo foi a referência para a reposição das lâminas aplicadas nas demais doses, segundo a equação 1 :

$\psi_{\mathrm{m}}=-12,6 \mathrm{~h}+\mathrm{h} 1+\mathrm{z}$

em que: $\psi_{\mathrm{m}}=$ potencial mátrico; $\mathrm{h}=$ altura da coluna de mercúrio $(\mathrm{Hg})$ na cuba $(\mathrm{cm}) ; \mathrm{h} 1=$ altura do nível de $\mathrm{Hg}$ na cuba $(\mathrm{cm})$, em relação à superfície do solo e $\mathrm{z}=$ profundidade da cápsula porosa $(10 \mathrm{~cm})$ (AMARO FILHO et al., 2008).

Ao final da irrigação, registrava-se a altura da coluna de $\mathrm{Hg}$ na cuba $(\mathrm{cm})$, que se apresentava com aproximadamente $5,0 \mathrm{~cm}$ para todos os tratamentos, ou seja, as condições de umidade no solo eram mantidas nas proximidades da capacidade de campo em todas as unidades experimentais (vasos).

A semeadura foi realizada utilizando-se em média 50 sementes por vaso, sendo efetuado o pré-desbaste oito dias após a germinação, permanecendo doze plantas por vaso, que foram reduzidas para três após o desbaste final, executado treze dias após a germinação.

Foram realizados três cortes, sendo o primeiro de uniformização, que teve como referência o comprimento horizontal do pseudocolmo, ou seja, todas as plantas dos vasos foram cortadas deixando um resíduo de $10 \mathrm{~cm}$ de comprimento de colmo, 43 dias após a semeadura. Esse critério foi adotado em busca da maior uniformização das plantas cortadas, visto que as mesmas apresentavam crescimento com diferentes graus de inclinação dos perfilhos, dificultando uma uniformidade de corte caso este fosse realizado a uma altura vertical fixa. O segundo e o terceiro corte obedeceram ao mesmo critério e foram realizados após um período de descanso de 28 dias.

As adubações fosfatadas (superfosfato simples), potássica (cloreto de potássio) e micronutrientes (FTE BR-12), foram realizadas de acordo com os resultados da análise do solo, assim como a aplicação do calcário calcítico. As aplicações de nitrogênio (uréia) e de potássio foram parceladas. No crescimento de estabelecimento (43 dias de crescimento) a dose de nitrogênio para cada tratamento foi dividida em duas, sendo a primeira metade aplicada logo após o desbaste final e a segunda metade sendo aplicada após 14 dias. Em todas as aplicações de nitrogênio, fez-se a diluição da uréia na água utilizada para a irrigação, buscando-se uma melhor uniformização de aplicação do fertilizante. O potássio foi disponibilizado em duas aplicações, sendo a primeira $\left(120 \mathrm{mg} \mathrm{dm}^{-3}\right.$ de $\left.\mathrm{K}_{2} \mathrm{O}\right)$ realizada logo na implantação (no momento da semeadura). A segunda aplicação de potássio $\left(120 \mathrm{mg} \mathrm{dm}^{-3}\right.$ de $\left.\mathrm{K}_{2} \mathrm{O}\right)$ via solução aquosa foi logo após o corte de uniformização, juntamente com a primeira dose de nitrogênio na rebrotação 1 . $\mathrm{O}$ fornecimento de fósforo $\left(125 \mathrm{mg} \mathrm{dm}^{-3} \mathrm{de}_{2} \mathrm{O}_{5}\right)$ foi de uma só vez, no ato da semeadura. Neste momento, foram fornecidos os micronutrientes (25 mg dm${ }^{-3}$ de FTE BR-12). A segunda metade da dose de nitrogênio para cada tratamento aplicada na rebrotação 1 foi disponibilizada na metade do período de descanso (ciclos de 28 dias). Na rebrotação 2, seguiu-se o mesmo manejo.

Ao final do último ciclo de avaliação (rebrotação 2), logo posteriormente ao corte, registrou-se a altura do resíduo pós-corte e todo o material residual pós-corte de cada unidade experimental (plantas no vaso) foi colhido e levado ao laboratório para separação dos componentes: folha, pseudocolmo (colmo + bainha) e material morto. Após a separação de tais componentes, as amostras foram encaminhadas para estufa de ventilação forçada $\left(55^{\circ} \mathrm{C}\right.$ até peso constante), para posterior determinação da massa seca de forragem total residual (MSFTr, em g/vaso), de forragem verde residual (MSFVr, em g/vaso), de forragem morta residual (MSFMr, em g/vaso), de lâmina foliar verde residual (MSLVr, em g/vaso), de colmo verde residual (MSCVr, em g/vaso), relação lâmina foliar/colmo residual $(\mathrm{LF} / \mathrm{C})$ e densidade populacional de perfilhos (DPP, em perfilhos/vaso). As raízes foram retiradas dos vasos, lavadas com água sob pressão em peneiras e encaminhadas para pré-secagem de modo a se calcular a produção de massa seca radicular (MS radicular, em g/vaso).

Os dados foram submetidos à análise de variância e análise de regressão. A escolha dos modelos baseou-se na significância dos coeficientes linear e quadrático, por meio do teste " $\mathrm{t}$ ", de Student 
$(\mathrm{P}<0,05)$ e no coeficiente de determinação. Como ferramenta de auxílio às análises estatísticas, adotouse o procedimento GLM, do programa estatístico SAS (SAS Institute, 2003).

\section{Resultados e discussão}

$\mathrm{O}$ incremento nas doses de adubo nitrogenado provocou alterações significativas $(\mathrm{P}<0,05)$ para as seguintes variáveis: altura do resíduo pós-corte, massa seca de forragem total residual, de forragem verde residual, de forragem morta residual, de colmo verde residual, relação lâmina foliar/colmo, densidade populacional de perfilhos, razão parte aérea/raiz e massa seca radicular, exceto para massa seca de lâmina foliar verde residual (TAB. 1), porém de acordo com Chew (1976), a análise de variância não é um pré requisito para as análises posteriores. Mesmo assim, os resultados verificados para tais variáveis demonstraram a relevância do nitrogênio sobre as características estruturais do resíduo pós-corte do capim-massai (TAB. 2).

Constatou-se resposta quadrática $(\mathrm{P}<0,05)$ na altura residual em função das doses de nitrogênio, apresentando valor mínimo $(8,86 \mathrm{~cm})$ na dose de $460 \mathrm{mg} \mathrm{dm}^{-3}$ de $\mathrm{N}$ (TAB. 2). Apesar disso, as diferenças para os valores brutos foram desprezíveis $(8,9$ a $10,0 \mathrm{~cm})$, devido ao fato do padrão de corte preconizado para todas as parcelas ter sido referenciado no comprimento horizontal do pseudocolmo, ou seja, todas as plantas dos vasos foram cortadas deixando um resíduo de $10 \mathrm{~cm}$ de comprimento de colmo.

A altura do resíduo pós-pastejo e pós-corte exerce um importante efeito sobre o vigor da rebrotação, visto que uma altura residual elevada apesar de favorecer o crescimento da planta sem mobilizar as reservas orgânicas, pode elevar o alongamento das hastes, com a concomitante elevação do meristema apical, e decapitação através do corte e/ou pastejo. Ademais, a altura de corte pode influenciar o acúmulo e a composição morfológica da forragem produzida (PENA et al., 2009), podendo ser usada para controlar o alongamento de colmos, fração indesejável e de composição bromatológica inferior àquela de lâminas foliares (BUENO, 2003). Portanto, a manutenção da altura residual adequada, tal como observada no presente trabalho propicia melhoria do vigor do pasto e rápida rebrotação, por meio de efeitos positivos sobre perfilhamento, levando à persistência e perenidade do pasto.

A densidade populacional de perfilhos (DPP) apresentou efeito linear crescente $(\mathrm{P}<0,05)$ ao aumento nas doses de nitrogênio, com estimativa de 102 e 156 perfilhos/ vaso nas doses 0 e $600 \mathrm{mg} \mathrm{dm}^{-3}$ de $\mathrm{N}$, respectivamente (TAB. 2). A dose de $600 \mathrm{mg} \mathrm{dm} \mathrm{de}^{-3} \mathrm{~N}$ proporcionou incremento de 52,9\% na DPP em relação ao tratamento com ausência de nitrogênio. Esse incremento do número de perfilhos por vaso na maior dose de adubação nitrogenada ocorreu possivelmente devido à ativação de tecidos meristemáticos, especialmente das gemas axilares na base do dossel, que agindo sinergicamente com a intensidade

Tabela 1 - Resumo da análise de variância para os componentes estruturais do resíduo pós-corte em Panicum maximum x Panicum infestum cv. Massai

\begin{tabular}{|c|c|c|c|c|c|c|c|}
\hline $\begin{array}{l}\text { Causas da } \\
\text { Variaçãoo }^{1}\end{array}$ & $\begin{array}{c}\text { G.L. } \\
\text { Modelo }\end{array}$ & $\begin{array}{l}\text { G.L. } \\
\text { Erro }\end{array}$ & $\begin{array}{l}\text { Q.M. } \\
\text { Modelo }\end{array}$ & $\begin{array}{l}\text { Q.M. } \\
\text { Erro }\end{array}$ & $\mathrm{F}$ & Signif. & CV (\%) \\
\hline Altura & 2 & 22 & 1,923 & 0,183 & 10,5 & 0,0006 & 4,65 \\
\hline DPP & 1 & 23 & 8925 & 60,59 & 147,3 & 0,0001 & 6,02 \\
\hline MSFTr & 1 & 23 & 2175 & 4,72 & 460,8 & 0,0001 & 8,18 \\
\hline MSFVr & 1 & 23 & 700,9 & 4,612 & 151,97 & 0,0001 & 12,49 \\
\hline MSFMr & 1 & 23 & 407,8 & 0,837 & 487,2 & 0,0001 & 9,77 \\
\hline MSLVr & 2 & 22 & 1,089 & 0,378 & 2,88 & 0,0775 & 38,63 \\
\hline MSCVr & 1 & 23 & 664,7 & 2,661 & 249,8 & 0,0001 & 10,45 \\
\hline $\mathrm{LF} / \mathrm{C}$ & 1 & 23 & 0,0288 & 0,0022 & 13,0 & 0,0015 & 47,18 \\
\hline $\mathrm{PA} / \mathrm{R}$ & 1 & 23 & 5,407 & 0,019 & 284,6 & 0,0001 & 6,78 \\
\hline MS raiz & 1 & 23 & 584,8 & 2,362 & 247,6 & 0,0001 & 7,50 \\
\hline
\end{tabular}

${ }^{1}$ Quadrado médio (Q.M.); F calculado (F); significância (Signif.); coeficiente de variação (CV); Altura do resíduo pós-corte (Altura), massa seca de forragem total residual (MSFTr), de forragem verde residual (MSFVr), de forragem morta residual (MSFMr), de lâmina foliar verde residual (MSLVr), de colmo verde residual (MSCVr), relação lâmina foliar/colmo (LF/C), densidade populacional de perfilhos (DPP), Razão parte aérea/raiz (PA/R) e Massa seca radicular (MS raiz) 
Tabela 2 - Características estruturais do resíduo pós-corte de Panicum maximum x Panicum infestum cv. Massai adubado com doses crescentes de nitrogênio

\begin{tabular}{|c|c|c|c|c|c|c|}
\hline \multirow{3}{*}{ Variável } & \multicolumn{5}{|c|}{ Tratamentos } & \multirow{3}{*}{ Equações } \\
\hline & 0 & 150 & 300 & 450 & 600 & \\
\hline & \multicolumn{5}{|c|}{$\mathrm{mg} \mathrm{dm}^{-3} \mathrm{de} \mathrm{N}$} & \\
\hline Altura $(\mathrm{cm})$ & 10,0 & 9,3 & 8,9 & 9,1 & 8,9 & $\begin{array}{c}\hat{\mathrm{Y}}=9,92-0,0046^{* *} \mathrm{~N}+0,000005^{*} \mathrm{~N}^{2} \\
\mathrm{R}^{2}=0,49\end{array}$ \\
\hline DPP (perf./vaso) & 99 & 119 & 129 & 148 & 151 & $\begin{array}{c}\hat{\mathrm{y}}=102,48+0,0891 * * \mathrm{~N} \\
\mathrm{R}^{2}=0,86\end{array}$ \\
\hline MSFTr (g MS/vaso) & 12,6 & 19,4 & 28,5 & 34,1 & 38,2 & $\begin{array}{c}\hat{\mathrm{y}}=13,35+0,04397 * * \mathrm{~N} \\
\mathrm{R}^{2}=0,95\end{array}$ \\
\hline MSFVr (g MS/vaso) & 8,9 & 13,0 & 19,0 & 21,8 & 23,2 & $\begin{array}{c}\hat{\mathrm{y}}=9,71+0,02496^{* *} \mathrm{~N} \\
\mathrm{R}^{2}=0,87\end{array}$ \\
\hline MSFMr (gMS/vaso) & 3,7 & 6,4 & 9,4 & 12,3 & 15,0 & $\begin{array}{c}\hat{\mathrm{y}}=3,65+0,01904 * * \mathrm{~N} \\
\mathrm{R}^{2}=0,95\end{array}$ \\
\hline MSLVr (g MS/vaso) & 1,10 & 1,5 & 2,1 & 1,8 & 1,5 & $\begin{array}{c}\hat{\mathrm{Y}}=1,08+0,0048 * \mathrm{x}-0,0000069 * \mathrm{~N}^{2} \\
\mathrm{R}^{2}=0,21\end{array}$ \\
\hline MSCVr (g MS/vaso) & 7,8 & 11,5 & 16,9 & 20,0 & 21,8 & $\begin{array}{c}\hat{\mathrm{y}}=8,31+0,0243^{* *} \mathrm{~N} \\
\mathrm{R}^{2}=0,92\end{array}$ \\
\hline $\mathrm{LF} / \mathrm{C}$ & 0,14 & 0,12 & 0,12 & 0,08 & 0,04 & $\begin{array}{c}\hat{\mathrm{y}}=0,148-0,00016^{* *} \mathrm{~N} \\
\mathrm{R}^{2}=0,36\end{array}$ \\
\hline $\mathrm{PA} / \mathrm{R}$ & 1,33 & 1,65 & 2,04 & 2,38 & 2,61 & $\begin{array}{c}\hat{\mathrm{y}}=1,34+0,002192 * * \mathrm{~N} \\
\mathrm{R}^{2}=0,93\end{array}$ \\
\hline MS raiz (g/vaso) & 12,22 & 17,79 & 22,00 & 24,44 & 26,00 & $\begin{array}{c}\hat{\mathrm{y}}=13,65+0,0228 * * \mathrm{~N} \\
\mathrm{R}^{2}=0,91\end{array}$ \\
\hline
\end{tabular}

Altura do resíduo pós-corte (Altura), massa seca de forragem total residual (MSFTr), de forragem verde residual (MSFVr), de forragem morta residual (MSFMr), de lâmina foliar verde residual (MSLVr), de colmo verde residual (MSCVr), relação lâmina foliar/colmo (LF/C), densidade populacional de perfilhos (DPP), razão parte aérea/raiz (PA/R) e massa seca radicular (MS raiz); $\hat{y}=$ valores estimados a partir da equação de regressão para cada variável analisada; $\mathrm{N}=$ dose de nitrogênio; significativo ao nível de $1 \%(* *)$ e $5 \%(*)$

luminosa, elevou a relação vermelho/vermelho distante no interior do dossel, favorecendo o aumento da DPP (WAN; SOSEBEE, 1998). Uma maior densidade populacional de perfilhos, proporcionada pelo efeito estimulante do nitrogênio sobre pontos de crescimento, com posterior manutenção dessa densidade, possibilitará uma resposta positiva sobre o vigor de rebrotação e persistência do capim-massai nos ciclos posteriores, através do melhor aproveitamento dos recursos produtivos utilizados na pastagem, como água, nutrientes, luz e temperatura.

A massa seca de forragem total residual (MSFTr), de forragem verde residual (MSFVr) e de forragem morta residual (MSFMr) responderam de forma linear positiva $(\mathrm{P}<0,05)$ às doses de nitrogênio, com valores estimados de 13,35 e $39,73 \mathrm{~g} \mathrm{MS} / \mathrm{vaso}$ para MSFTr, de 9,71 e 24,69 g MS/vaso para MSFVr e de 3,65 e 15,07 g MS/vaso para MSFMr nas doses de
0 a $600 \mathrm{mg} \mathrm{N} \mathrm{dm}^{-3}$ de solo, respectivamente (TAB. 2). Os incrementos em biomassa foram de 197,6\%; 154,3\% e $312,9 \%$ para MSFTr, MSFVr e MSFMr, respectivamente, quando comparado o controle (ausência de nitrogênio) com a maior dose de adubação nitrogenada $\left(600 \mathrm{mg} \mathrm{N} \mathrm{dm}^{-3} \mathrm{de}\right.$ solo).

Tal resposta em aumento de biomassa se explica pelo fato da adubação nitrogenada acelerar o crescimento (SANTOS JÚNIOR et al., 2004), o perfilhamento, a produção de folha e, conseqüentemente, o aumento da massa seca na parte aérea (MARTUSCELLO et al., 2006), justificando o incremento na biomassa residual do capim-massai.

Pode-se inferir que o principal responsável pela elevação da MSFTr e MSFVr nas maiores doses de nitrogênio foi o aumento do número de perfilhos, visto que 
esta variável respondeu crescentemente ao incremento na adubação nitrogenada e a DPP apresentou alta correlação com a MSFTr e MSFVr $(\mathrm{R}=0,95$ e $\mathrm{R}=0,93$, respectivamente). A superioridade na MSFMr com a elevação das doses de nitrogênio possivelmente deveu-se ao efeito do nitrogênio sobre os processos fisiológicos na planta, pois apesar de não ter havido efeito sobre a taxa de senescência foliar (dados não apresentados), houve morte de perfilhos em função da decapitação do meristema apical com os sucessivos ciclos, levando ao acúmulo de material morto e proporcionando maior incremento na MSFMr.

A massa seca de lâmina foliar verde residual (MSLVr) revelou resposta quadrática $(\mathrm{P}<0,05)$ com o aumento nas doses de nitrogênio (TAB. 2), com valores estimados em 1,08 e 1,48 g MS/vaso para as doses de 0 e $600 \mathrm{mg} \mathrm{dm}^{-3}$ de $\mathrm{N}$, com ponto de máximo de 2,75 $\mathrm{g} \mathrm{MS} /$ vaso com $347,8 \mathrm{mg} \mathrm{dm}^{-3} \mathrm{de}$ $\mathrm{N}$, que associado ao comportamento decumbente das folhas, elevou o coeficiente de extinção luminosa no interior do dossel, com a consequente alteração na composição morfológica da planta. Ademais, a resposta decumbente pode ter sido um mecanismo de escape da planta, mantendo o meristema apical mais distante da altura de corte (POMPEU et al., 2009), especialmente nas maiores doses de nitrogênio, que podem ter intensificado o desenvolvimento das hastes e conseqüentemente ter elevado o meristema apical. A MSLVr tem um papel fundamental na rebrotação do pasto, pois a área foliar verde remanescente após o pastejo é diretamente proporcional à taxa de fotossíntese líquida do pasto(GOMIDE et al., 2002), e quanto maior seu valor, menor será a mobilização de reservas orgânicas pelo meristema apical para a reposição de folhas (RODRIGUES; RODRIGUES, 1987).

A maior produção de MSLVr nas plantas recebendo as maiores doses de nitrogênio, provavelmente irá refletir em IAF residual superior ao IAF residual das plantas com ausência e supridas pelas menores doses de nitrogênio, resultando em uma melhor condição de rebrotação para as plantas com maior aporte desse nutriente. Dessa forma, diminuindo o período de participação das reservas do colmo para formação de novas folhas e restaurando mais rapidamente os teores de carboidratos totais não-estruturais.

Vale ressaltar, que a gramínea em estudo apresentou taxa de alongamento de hastes insignificante nas maiores doses de nitrogênio, que associada a uma elevada densidade populacional de perfilhos contribuiu para uma superioridade no IAF residual, favorecendo a rebrotação. A quantidade de folhas remanescentes na planta pastejada indica o nível de pressão de pastejo e a supressão da seletividade do pastejo exercida pelo animal, que prefere folhas ao invés de colmos. Dessa forma, se há poucas folhas remanescentes, pode-se inferir que a pressão de pastejo foi alta e que, conseqüentemente, a seletividade foi mínima (HILLESHEIM; CORSI, 1990).

A massa seca de colmo verde residual (MSCVr) respondeu crescentemente $(\mathrm{P}<0,05)$ com o aumento nas doses de nitrogênio, com valores estimados em 8,31 e $22,89 \mathrm{~g} \mathrm{MS} /$ vaso para 0 e $600 \mathrm{mg} \mathrm{dm}^{-3} \mathrm{de} \mathrm{N}$, respectivamente (TAB. 2). Para cada $1 \mathrm{mg} \mathrm{dm}^{-3}$ de $\mathrm{N}$ aplicado houve acréscimos de 0,0243 g MS/vaso sobre a MSCVr, justificado pelo aumento na densidade populacional de perfilhos nas doses superiores, confirmado pela alta correlação entre ambas varáveis $(\mathrm{R}=0,94)$. Apesar de responder em incrementos na produção de forragem, aumento na MSCV reflete em efeitos negativos na qualidade da forragem produzida e no seu aproveitamento pelos animais em pastejo (SILVA et al., 2007a), devido à redução do consumo voluntário de matéria seca pelo animal (CÂNDIDO, et al., 2006), em decorrência do espessamento da parede celular vegetal secundária, com o acúmulo de lignina e de carboidratos estruturais menos digestíveis (WILSON; KENNEDY, 1996).

A relação lâmina foliar residual/colmo (LF/C) decresceu $(\mathrm{P}<0,05)$ com o incremento nas doses de nitrogênio, estimados em 0,15 e 0,05 para 0 e $600 \mathrm{mg} \mathrm{dm}^{-3} \mathrm{de}$ $\mathrm{N}$, respectivamente (TAB. 2). Tal comportamento é justificado pelo fato do maior incremento em biomassa de pseudocolmo em relação à biomassa foliar para as plantas que receberam maior dose de nitrogênio, em resposta à maior densidade populacional de perfilhos, refletindo em redução na relação $\mathrm{LF} / \mathrm{C}$ residual.

As variáveis massa seca radicular (MS raiz) e a razão parte aérea/raiz (PA/R) estudadas durante a rebrotação 2 apresentaram valores superiores $(\mathrm{P}<0,05)$ com a elevação da adubação nitrogenada, revelando comportamento linear crescente para ambas as variáveis (TAB. 2). Verificou-se que a MS raiz variou de 13,65 a $27,33 \mathrm{~g} /$ vaso e a razão $\mathrm{PA} / \mathrm{R}$ de 1,34 a 2,66 para as doses de 0 a $600 \mathrm{mg} \mathrm{dm}^{-3}$ de $\mathrm{N}$, respectivamente. A dose de $600 \mathrm{mg} \mathrm{dm}^{-3}$ de $\mathrm{N}$, proporcionou um incremento de $100,2 \%$ na MS raiz e 98,5\% na razão $\mathrm{PA} / \mathrm{R}$, em relação ao tratamento com ausência de nitrogênio (TAB. 2).

O aumento na MS de raiz com a elevação das doses de nitrogênio pode ser justificado pela elevada DPP verificada nas maiores doses, associado a um aumento na MSFVr e MSLVr, pois de acordo Sarmento et al. (2005) e Sarmento et al. (2008), a menor massa de raiz em ausência de adubação nitrogenada está relacionada à baixa quantidade de massa seca de lâminas foliares no póspastejo e ao baixo IAF residual das plantas não adubadas. Cecato et al. (2001), estudando massa de raízes em pastos de Coastcross-1, verificaram que a produção de massa seca radicular aumentou à medida que se elevaram os níveis do 
resíduo da parte aérea. A resposta na produção de massa seca de raízes do capim-massai, ratifica a relevância de uma planta estar bem suprida de nitrogênio para que possa apresentar um sistema radicular bem desenvolvido e consolidado, pois de acordo com Whitehead (1990) a deficiência de nitrogênio prejudica o crescimento do sistema radicular.

O incremento apresentado pela massa de raiz e razão parte aérea/raiz, demonstra a importância da adubação nitrogenada para um balanço positivo entre parte aérea e sistema radicular para uma resposta satisfatória em produtividade nas forrageiras manejadas intensivamente. Tal incremento em massa de raiz proporciona uma melhor consolidação do sistema radicular, com maior capacidade de respostas em termos de absorção de nutrientes (maior área explorada), resultado de um maior volume de solo ocupado pelas raízes, com conseqüentes respostas na biomassa do dossel, o que foi observado pela maior biomassa produzida (dados não apresentados) nas maiores doses de nitrogênio, constatado no presente estudo.

\section{Conclusão}

A adubação nitrogenada proporciona respostas positivas sobre as características estruturais do resíduo póscorte do capim-massai, com a maioria dos componentes analisados respondendo até a dose de $600 \mathrm{mg} \mathrm{de} \mathrm{N} \mathrm{dm}^{-3}$ de solo.

\section{Agradecimentos}

À SESu, especialmente ao Programa de Educação Tutorial (PET), pelo auxílio financeiro e concessão das bolsas.

\section{Referências}

AMARO FILHO, J.; ASSIS JÚNIOR, R. N.; MOTA, J. C. A. Física do solo: conceitos e aplicações. Fortaleza. Imprensa Universitária, 2008. 290 p.

BRISKE, D. D. Strategies of plant survival in grazed systems: a functional interpretation. In: HODGSON, J.; ILLIUS, A. W. The ecology and management of grazing systems. Wallingford: CAB International, 1996. p. 37-67.

BUENO, A. A. O. Características estruturais do dossel forrageiro, valor nutritivo e produção de forragem em pastos de capim-Mombaça submetidos a regimes de desfolhação intermitente. Piracicaba, SP: ESALQ, 2003. Dissertação
(Mestrado em Agronomia) - Escola Superior de Agricultura Luiz de Queiroz, Piracicaba.

CÂNDIDO, M. J. D. et al. Fluxo de biomassa em capim-tanzânia pastejado por ovinos sob três períodos de descanso. Revista Brasileira de Zootecnia, v. 35, n. 06, p. 2234-2242, 2006.

CECATO, U. et al. Teores de carboidratos não-estruturais, nitrogênio total e peso de raízes em Coastacross-1 (Cynodon dactylon L.) Pers) pastejado por ovinos. Revista Brasileira de Zootecnia, v. 30, n. 03, p. 644-650, 2001.

CHEW, V. Comparing treatment means: a compendium. Hortscience, v. 11, n. 04, p. 348-357, 1976.

COMISSÃO DE FERTILIDADE DO SOLO DO ESTADO DE MINAS GERAIS (CFSEMG). Recomendações para uso de corretivos e fertilizantes em Minas Gerais - $5^{\text {a }}$ Aproximação. 5. ed. Viçosa: UFV, 1999. 359 p.

DIFANTE, G. S. et al. Ingestive behaviour, herbage intake and grazing efficiency of beef cattle steers on Tanzania guineagrass subjected to rotational stocking managements. Revista Brasileira de Zootecnia, v. 38, n. 06, p. 1001-1008, 2009.

DURU, M.; DUCROCQ, H. Growth and senescence of the successive leaves on a Cocksfoot tiller. Effect of nitrogen and cutting regime. Annals of Botany, v. 85, n.05, p. 645-653, 2000.

FAGUNDES, J. L. et al. Avaliação das características estruturais do capim-braquiária em pastagens adubadas com nitrogênio nas quatro estações do ano. Revista Brasileira de Zootecnia, v. 35, n. 01, p. 30-37, 2006.

GARCEZ NETO, A. F. et al. Respostas morfogênicas e estruturais de Panicum Maximum cv. Mombaça sob diferentes níveis de adubação nitrogenada e alturas de corte. Revista Brasileira de Zootecnia, v. 31, n. 05, p. 1890-1900, 2002.

GOMIDE, C. A. M. et al. Fotossíntese, reservas orgânicas e rebrota do capim-mombaça (Panicum maximun Jacq.) sob diferentes intensidades de desfolha do perfilho principal. Revista Brasileira de Zootecnia, v. 31, n. 06, p. 2165-2175, 2002.

HILLESHEIM, A.; CORSI, M. Capim elefante sob pastejo. II. Fatores que afetam as perdas e utilização de matéria seca. Pesquisa Agropecuária Brasileira, v. 25, n. 09, p. 12331246, 1990.

MAGALHÃES, J. A. et al. Influência da adubação nitrogenada e da idade de corte sobre o rendimento forrageiro do capim-elefante. Revista Ciência Agronômica, v. 37, n. 01, p. 91-96, 2006.

MARTUCESLlO, J. A. et al. Características morfogênicas e estruturais de capim-massai submetido a adubação nitrogenada e desfolhação. Revista Brasileira de Zootecnia, v. 35, n. 03, p. 665-671, 2006.

MORAES, A. Produtividade animal e dinâmica de uma pastagem de pangola (Digitaria decumbens sten), azevém (Lolium multiflorum Lam.) e trevo branco (Trifolium repens L.) submetida a diferentes pressões de pastejo. 1991. $200 \mathrm{f}$. Tese (Doutorado em Zootecnia) - Universidade Federal do Rio Grande do Sul, Porto Alegre.

PENA, K. S. et al. Características morfogênicas, estruturais 
e acúmulo de forragem do capim-tanzânia submetido a duas alturas e três intervalos de corte. Revista Brasileira de Zootecnia, v. 38, n. 11, p. 2127-2136, 2009.

POMPEU, R. C. F. F. et al. Fluxo de biomassa em capim-tanzânia sob lotação rotativa com quatro níveis de suplementação concentrada. Revista Brasileira de Zootecnia, v. 38, n. 05, p. 809-817, 2009.

REZENDE, C. P. et al. Dinâmica de perfilhamento e fluxo de biomassa em capim-cameroon sob lotação rotativa. Revista Brasileira de Zootecnia, v.37, n.10, p.1750-1757, 2008.

RODRIGUES, L. R. A.; RODRIGUES, T. J. D. Ecofisiologia de plantas forrageiras. In: CASTRO, P. R. C.; FERREIRA, S. O.; YAMADA, T. Ecofisiologia da produção agrícola. Piracicaba: Associação Brasileira para Pesquisa da Potassa e do Fosfato, 1987. p. 203-230.

SANTOS JÚNIOR, J. D. G.; MONTEIRO, F. A.; JUNIOR, J. L. Análise de crescimento do capim-marandu submetido a doses de nitrogênio. Revista Brasileira de Zootecnia, v. 33, n. 06, p. 1985-1991, 2004.

SARMENTO, P. et al. Respostas agronômicas e morfológicas de Panicum maximum Jacq. cv. IPR-86 Milênio, sob pastejo, à adubação nitrogenada. Boletim da Indústria Animal, v.
62, p. 333-346, 2005 .

SARMENTO, P. et al. Sistema radicular do Panicum maximum Jacq. cv. IPR-86 Milênio adubado com nitrogênio e submetido à lotação rotacionada. Revista Brasileira de Zootecnia, v. 37, n. 01, p. 27-34, 2008.

SAS INSTITUTE. SAS System for Windows. Version 9.0. Cary: SAS Institute Inc., 2003. 2 CD-ROMs.

SILVA, R. G. et al. Características estruturais do dossel de pastagens de capim-tanzânia mantidas sob três períodos de descanso com ovinos. Revista Brasileira de Zootecnia, v. 36, n. 05, p. 1255-1265, 2007a.

WAN, C.; SOSEBEE, R. E. Tillering responses to red:far-red light ratio during different phenological stages in Eragrostis curvula. Environmental and Experimental Botany, v. 40, n. 03, p. 247-254, 1998.

WHITEHEAD, D. C. Grassland Nitrogen. Wallingford: CAB International, 1990. $397 \mathrm{p}$.

WILSON, J. R.; KENNEDY, P. M. Plant and animal constraints to voluntary feed intake associated with fibre characteristics and particle breakdown and passage in ruminants. Australian Journal of Agricultural Research, v .47, n. 02, p. 199-225, 1996. 